\title{
Electroactive Polymer Actuator Online Database
}

\author{
J.D. Madden*, N. Genereux, K.A. Shkuratoff, A. van der Star, D. Poon, \\ D. Irwin, P.Cheng, G. Hsu, L. Filipozzi. \\ ${ }^{a}$ Department of Electrical \& Computer Engineering, University of British Columbia, Vancouver, \\ British Columbia, V6T 1Z4, Canada
}

\begin{abstract}
As polymer actuator performance improves there is an increasing demand to understand and compare properties. Past comparisons have relied on general statements of properties but do not capture the interdependence of these properties or keep up with the rapid pace of change. Modeling such interdependencies is complex. An alternative is to compile many measurements. A new actuator database has been created that is a compilation of experimental methods and results (mechanical, electrical, chemical and other properties) combined with a web interface. The objective is to capture actuator performance under a wide variety of conditions. The current content of the page is presented and justified. Researchers may submit data to the web page via an online form.
\end{abstract}

Keywords: EAP, conducting polymers, dielectric elastomers, ferroelectric polymers, IPMC, ionomeric polymer metal composites, carbon nanotubes, review, comparison, properties.

\section{INTRODUCTION}

How does a designer decide if a particular actuator is appropriate for their task? How can a researcher decide what properties need to be improved, or compare their materials performance with that of others? This task is particularly challenging for electroactive polymers since they are emerging materials. The database described here and found at actuatorweb.org should help this process by presenting numbers extracted from measurements. So far results from more than 100 experiments on conducting polymer, carbon nanotube and dielectric elastomer actuators have been entered. The conditions under which each of the experiments performed in each paper were performed have been entered into the database.

\section{DATABASE INTERFACE DESCRIPTION}

When accessing actuatorweb.org the title page provides 6 primary options on the left hand column, as shown in Figure 1: ACTUATOR SUMMARY, ACTUATOR SELECTION, ACTUATOR COMPARISON, DATABASE BROWSER, FIELD OVERVIEW and DATA SUBMISSION. Actuator selection is meant to help designers choose a material that suits their needs, while the comparisons section allows ready extraction of trends and developments in the field of electroactive polymers. All categories are now described.

\subsection{ACTUATOR SUMMARY}

ACTUATOR SUMMARY is a static table that provides information as well as pros and cons for each actuator technology listed. Currently this table dates back to $2004^{1}$ and so does not mention recent advances, such a increased strain in conducting polymers and operation without leakage current in ionic polymer metal composites. However it does provide general information that is useful in comparing actuator types and in making a pre-selection of actuator types for specific applications.

\subsection{ACTUATOR SELECTION}

ACTUATOR SELECTION enables device designers to enter the approximate dimensions, force, displacement, time, cycle life, energy source and acceptable voltage range, in text boxes, shown in Figure 1. A number of properties are then

*jmadden at ece.ubc.ca; mm.ece.ubc.ca or actuatorweb.org .

Electroactive Polymer Actuators and Devices (EAPAD) 2007, edited by Yoseph Bar-Cohen, Proc. of SPIE Vol. 6524, 65240P, (2007) · 0277-786X/07/\$18 · doi: 10.1117/12.718042 
calculated, including the volume, power and work density. Selecting "Find Actuators" helps guide which actuators are able to provide the work needed within the specified volume, and which ones can use multiple strokes in order to achieve the work. The page also provides some idea of how much mechanical amplification will be needed. For example if the strain of a carbon nanotube actuator is only $0.5 \%$, the device length is $10 \mathrm{~mm}$ and the needed displacement is 1 $\mathrm{mm}$, the displacement produced by a carbon nanotube actuator placed along the length is only $0.05 \mathrm{~mm}$ and needs to be amplified by a factor of 20 to provide the needed displacement. This can be done using levers and other mechanisms, but does require additional engineering and expense. The methods used to compute the effectiveness of an actuator are the same as those used in the web page mm.ece.ubc.ca/actuator, and described in the 2005 proceedings of this conference. The main difference is that the old web page has a single value of strain, stress and other properties for each class of actuator, rather than linking the response that has been achieved to measurement conditions.

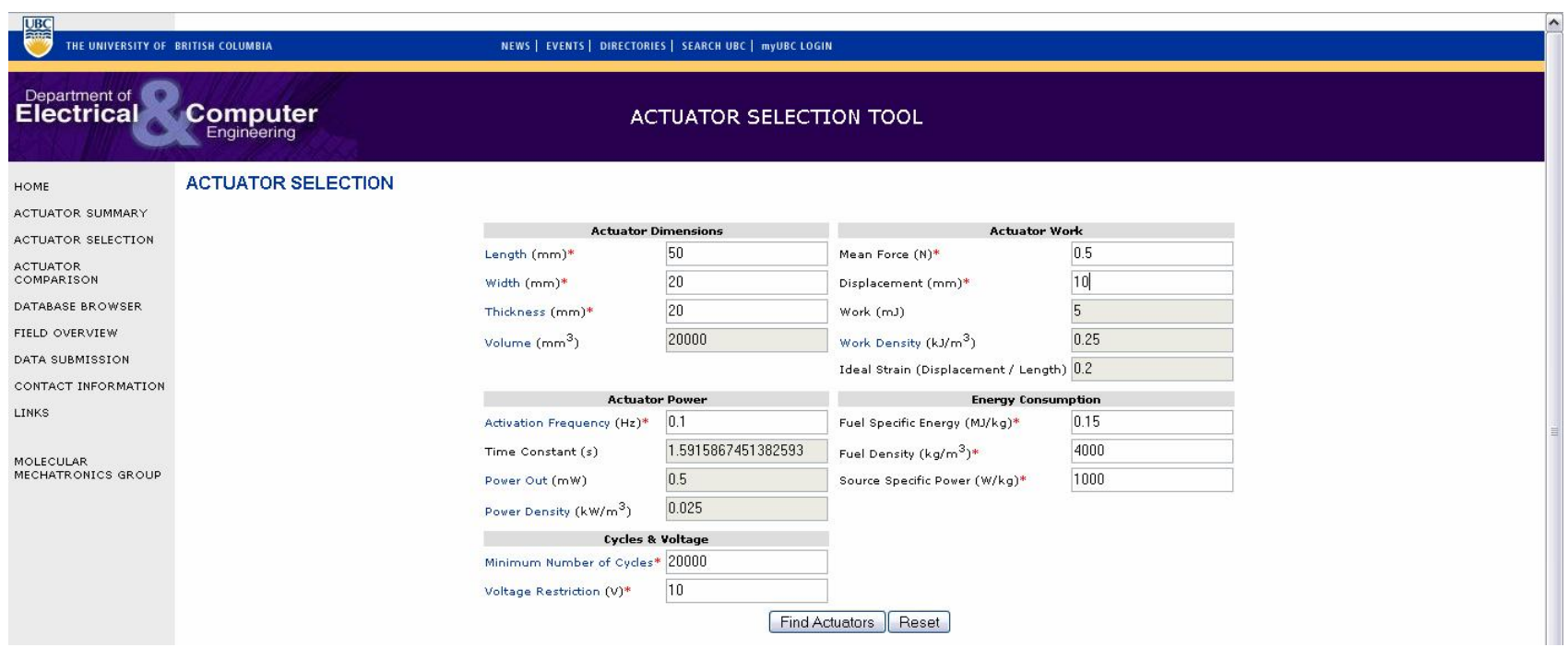

Fig. 1. The actuator selection tool input screen. Users input specifications into the white boxes. Selecting "Find Actuators" will result in the page shown in Figure 2. The left hand column is a list of the tools and features available on actuatorweb.org.

The actuator selection tool also estimates how much battery is needed in order to drive the actuator over the selected number of cycles. The battery or power source can end up being much larger than the actuator itself when operation over many cycles is required.

A key point to remember for all the comparisons is that stored numbers such as work density and power to mass are normalized by the actuator dimensions only, and do not include packaging, electrolyte, separators, pre-straining mechanisms, connectors and other items whose size does not necessarily scale linearly in proportion to work or force output. For this reason, when selecting actuator technologies it is advisable to chose those that easily meet the work and power requirements.

Figure 1 shows some example input parameters that might be appropriate for the development of an artificial urinary sphincter, and Figure 2 shows the resulting output.

From Figure 2 it is clear that nearly all of the actuators shown are able to do the work required and meet the power specifications despite the volume constraints. Selection may then be performed based on other properties. For example some of the actuators require extremely large mechanical amplification due to their small strain. This adds an extra challenge to the design.

At present the cycle life and voltage constraints set by the user do not prevent data that do not meet these requirements from being displayed. The reason for the omission of the cycle life specifications is that there is very little data to date on this property. The voltage constraint will be included on an upcoming upgrade. 


\subsection{Actuator Comparison Plots}

The ACTUATOR COMPARISON section allows users to plot any two of the properties stored in the database. Up to four simultaneous plots can be created. This allows users to explore the database graphically. This exploration shows similarities and differences between types of actuators, and also points out the tradeoffs between different properties. For example in Figure 3 the stresses and strains achieved in conducting polymer actuators are plotted. From this plot it is clear that high stresses can be achieved (62 MPa in this case) and high strains (13\%), but that these properties have not been achieved simultaneously.
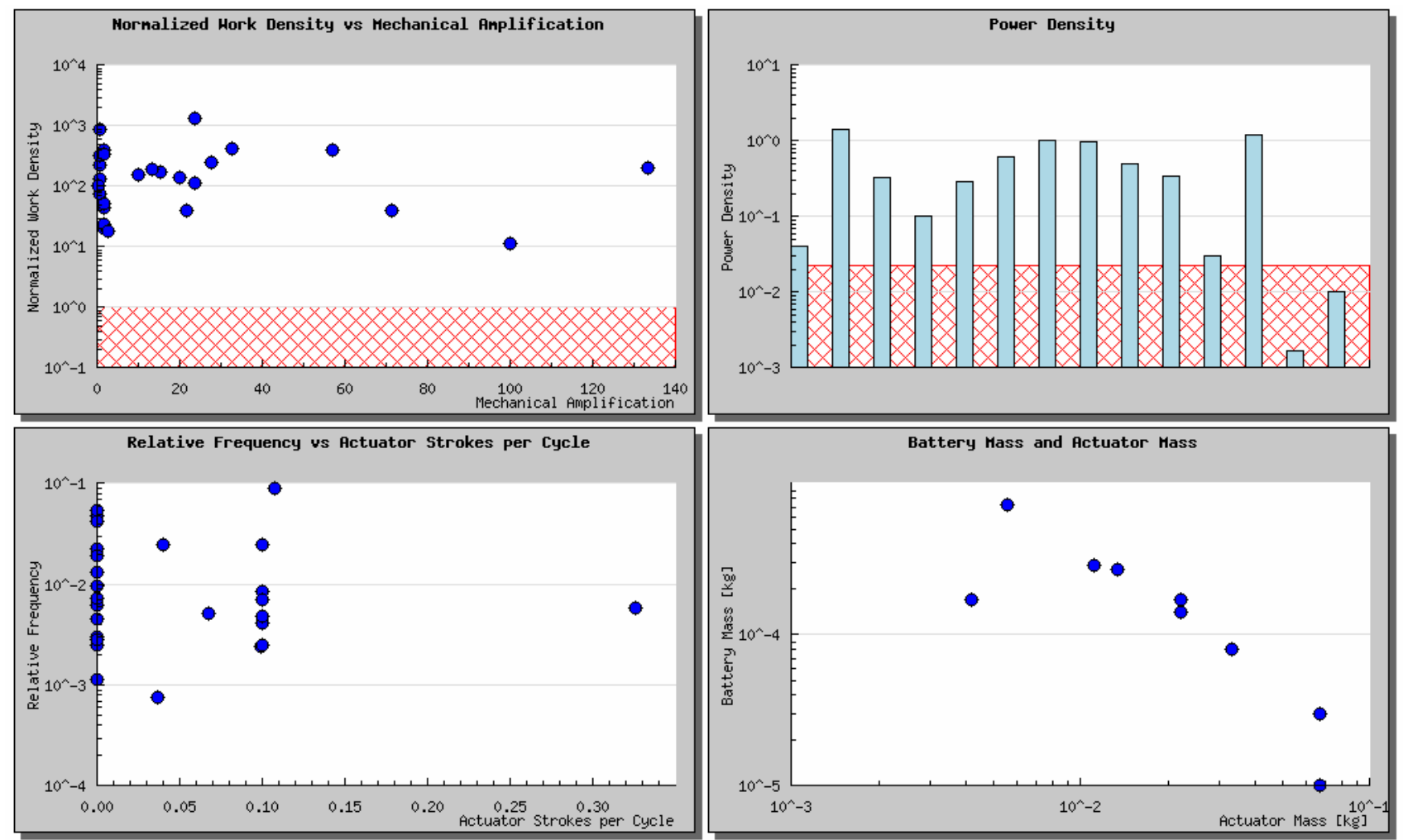

Fig. 2. The input shown in Figure 1 leads to the output screen shown here. The red hatching indicates the region in which the actuators fail to meet the work density and power density specifications. The top right plot indicates by what factor the work per unit volume of actuator exceeds the minimum value. The top right plot shows which actuators meet the minimum power requirements. The bottom left plot indicates how fast the actuator must cycle if it is to produce the work in one stroke, normalized by the desired actuation frequency. In this case the actuation rate is slow $(0.1 \mathrm{~Hz})$ and the allowed volume is quite large, so actuators don't need to perform a full cycle in the allotted time in order to complete the work, as is evident from the low relative frequency and by the strokes needed which are less than one.

Any data point in the plots can be selected to look at the full data set and the origin. Placing the cursor over any data point leads to the appearance of a descriptor. Clicking on the point produces the database record for that point. Recently the stresses at which conducting polymer actuators have been shown to operate have greatly increased. Selecting the highest stress dot (as seen in Figure 3) produces the database entries shown in Figure 4. A description of the fields is provided in Figure 5. Note that not all the fields need to be filled out and they are not all relevant. An attempt is made to be complete, but where complete details are needed, these can be obtained by selecting the reference at the bottom of the list, which finds the source with the assistance of Google Scholar. 


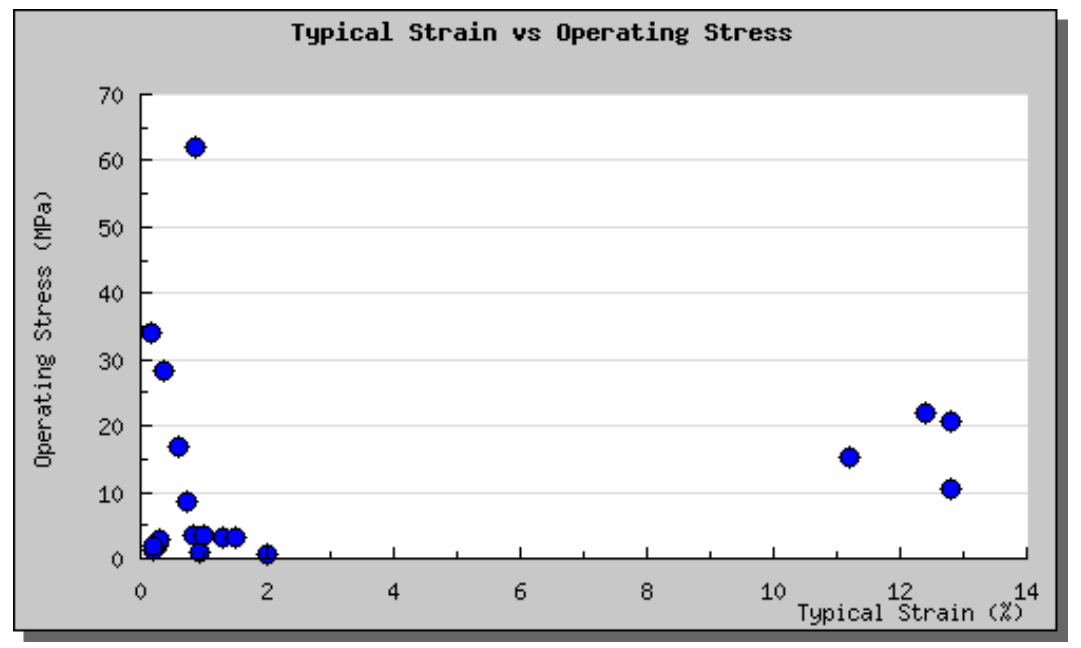

Fig. 3. Plot of operating stress versus typical strain for conducting polymers.

\begin{tabular}{|c|c|c|c|}
\hline \multicolumn{2}{|l|}{ Material Properties } & & \\
\hline Mechanism & $\mathrm{CP}$ & & \\
\hline Material & Polyaniline & & \\
\hline Additive & $0.76 \%$ CNT & & \\
\hline Density $(\mathrm{kg} / \mathrm{m} \wedge 3)$ & 1500 & & \\
\hline Dielectric Constant & & Experiment Results & \\
\hline Conductivity $(\mathrm{S} / \mathrm{cm})$ & 716 & Work Density $\left(\mathrm{kJ} / \mathrm{m}^{\wedge} 3\right)$ & 325 \\
\hline Young's Modulus (GPa) & 7.3 & Typical Strain (\%) & 0.85 \\
\hline Tensile Strength (MPa) & 255 & Operating Stress (MPa) & 62 \\
\hline Strain at Break (\%) & 4 & Power Density $\left(\mathrm{kW} / \mathrm{m}^{\wedge} 3\right)$ & 1.2 \\
\hline Geometry & & Continuous Power (W/kg) & \\
\hline Form & fiber & Cycles (Minimum) & \\
\hline Length (mm) & & Efficiency (\%) & \\
\hline Width (mm) & & $\begin{array}{l}\text { Electrochemical Strain } \\
\text { Coefficient }\left(\% /\left(\mathrm{c} / \mathrm{m}^{\wedge} 3\right)\right)\end{array}$ & \\
\hline Thickness (mm) & & $\begin{array}{l}\text { Coefticlent }\left(\% /\left(\mathrm{C} / \mathrm{m}^{\wedge} 3\right)\right) \\
\text { Charge }(\mathrm{mc})\end{array}$ & \\
\hline Outer Diameter (mm) & & Charge $(\mathrm{mc})$ & \\
\hline Inner Diameter (mm) & & Capacitance (F) & \\
\hline Volume $\left(\mathrm{mm}^{\wedge} 3\right)$ & & Bandwidth $(\mathrm{Hz})$ & \\
\hline Number of Strands & & Strain Rate $(\% / s)$ & \\
\hline Turns (turns/cm) & & Stress Rate $(\mathrm{MPa} / \mathrm{s})$ & \\
\hline Electrode Properties & & $\begin{array}{l}\text { Stress Relax Rate (Active) } \\
\text { (\%/cycle) }\end{array}$ & \\
\hline Name of Material & & Stress Relax Rate & \\
\hline Electrolyte Properties & & (Inactive) (\%/cycle) & \\
\hline Solvent Type & $\mathrm{AQ}$ & Creep Rate (Active) & 0.1 \\
\hline 1st Solvent & $\mathrm{H} 2 \mathrm{O}$ & (\%/cycle) & \\
\hline 2nd Solvent & & $\begin{array}{l}\text { Creep Rate (Inactive) } \\
\text { (\%/cycle) }\end{array}$ & \\
\hline Salt & $\mathrm{HCl}$ & Peak Power (W/kg) & 2.51 \\
\hline Concentration (M) & 1 & Peak Engineering Strain & \\
\hline Ratio (1st:2nd Solution) & & $(\%)$ & \\
\hline $\mathrm{pH}$ & & Average Strain Rate $(\% / s)$ & 0.01 \\
\hline Anion & $\mathrm{Cl}-$ & Average Stress Rate & 0.44 \\
\hline Cation & $\mathrm{H}+$ & $(\mathrm{MPa} / \mathrm{s})$ & \\
\hline Coating Material & & Charge/Nolume $\left(\mathrm{mC} / \mathrm{m}^{\wedge} 3\right)$ & \\
\hline Isometric or Isotonic & isotonic & Charge/Mass (mC/kg) & \\
\hline Operating Conditions & & CapacitanceNolume & \\
\hline Type of Cycling & $\mathrm{CV}$ & & \\
\hline Voltage Min. (V) & -0.2 & $\begin{array}{l}\text { Electric Field Intensity } \\
(\mathrm{V} / \mathrm{m})\end{array}$ & \\
\hline Voltage Max. (V) & 0.5 & Source Information & \\
\hline Voltage Difference $(V)$ & 0.7 & Source & $\begin{array}{l}\text { Carbon-Nanotube-Reinforced Polyaniline Fibers } \\
\text { for High-Strength Artificial Muscles }\end{array}$ \\
\hline $\begin{array}{l}\text { Prestrain (Primary Axis) (\%) } \\
\text { Prestrain (Secondary Axis) (\%) }\end{array}$ & & Author & \\
\hline Constant Load $(\mathrm{N})$ & & & Bahrami-Saniani, P.G. Whitten, G.G. Wallace \\
\hline Frequency $(\mathrm{Hz})$ & & Done & \\
\hline
\end{tabular}

Fig. 4. The list of the properties available in the database, and values from one of the database entries. Explanations of the categories are given in Figure 5 


\begin{tabular}{|c|c|}
\hline \multicolumn{2}{|l|}{ Material Properties } \\
\hline Mechanism & $\begin{array}{l}\text { A word that generally describes the class of materials used for actuation (e.g. Dielectric } \\
\text { Elastomer or Conducting Polymer or Carbon Nanotubes). }\end{array}$ \\
\hline Material & $\begin{array}{l}\text { The particular active material used (e.g. Silicone or polypyrrole or Multiwall Carbon } \\
\text { Nanotubes). }\end{array}$ \\
\hline Additive & $\begin{array}{l}\text { Additional material additive (e.g. particles to increase dielectric constant or influence } \\
\text { mechanical properties). }\end{array}$ \\
\hline Density $\left(\mathrm{kg} / \mathrm{m}^{\wedge} 3\right)$ & Density of the active material. \\
\hline Dielectric Constant & $\begin{array}{l}\text { Relative dielectric permittivity. Most relevant in dielectric elastomers, ferroelectric elastomers } \\
\text { and other electronic EAPs. }\end{array}$ \\
\hline Conductivity $(\mathrm{s} / \mathrm{cm})$ & $\begin{array}{l}\text { Electronic conductivity along the primary direction in which current flows. Not relevant for } \\
\text { dielectrics. }\end{array}$ \\
\hline Young's Modulus (GPa) & The normalized stiffness of the active material along the primary actuation axis. \\
\hline Tensile Strength (MPa) & The stress above which mechanical failure commonly occurs. \\
\hline Strain at Break (\%) & The relative elongation at which the material fails. \\
\hline \multicolumn{2}{|l|}{ Geometry } \\
\hline Form & Fiber, film, tube, bilayer or other geometry. \\
\hline Length $(\mathrm{mm})$ & Length of the active material along the primary axis of actuation. \\
\hline Width (mm) & Width of the active material. \\
\hline Thickness (mm) & Thickness of the active material (not including packaging, separators etc.). \\
\hline Outer Diameter (mm) & The diameter of the active material (in the case of a fiber or tube). \\
\hline Inner Diameter (mm) & The inner diameter of the active material (in the case of a tube). \\
\hline Volume $\left(\mathrm{mm}^{\wedge} 3\right)$ & The volume of active materials used. \\
\hline Number of Strands & If multiple films, fibers or tubes are used, how many of them are there? \\
\hline Turns (turns/cm) & If the active material is wound, how tight is the winding? \\
\hline \multicolumn{2}{|l|}{ Electrode Properties } \\
\hline Name of Material & What material is used to make electrical contact with the active material? \\
\hline \multicolumn{2}{|l|}{ Electrolyte Properties } \\
\hline Solvent Type & $\begin{array}{l}\text { The type of solvent in which ions are dissolved (e.g. aqueous, organic, ionic liquid, gel or solid } \\
\text { electrolyte). }\end{array}$ \\
\hline 1st Solvent & The dominant solvent (e.g. aqueous, acetonitrile etc.). \\
\hline 2nd Solvent & In case of a mixture, the second largest component (e.g. ethylene carbonate). \\
\hline Salt & $\begin{array}{l}\text { The chemical name for the ions added (e.g. Sodium Chloride or Tetrabutylammonium } \\
\text { hexafluorophosphate). }\end{array}$ \\
\hline Concentration (M) & The salt concentration. \\
\hline Ratio (1st:2nd Solution) & The relative proportions of the first and second solvents. \\
\hline $\mathrm{pH}$ & The $\mathrm{pH}$ (when aqueous solutions are used). \\
\hline Anion & The anion name (repetition of salt category above). \\
\hline Cation & The cation name (repetition of salt category above). \\
\hline Coating Material & Metal, dielectric or other material that coats the electrode. \\
\hline Isometric or Isotonic & Is the testing done under constant load (isotonic), constant length (isometric) or other? \\
\hline \multicolumn{2}{|l|}{ Operating Conditions } \\
\hline Type of Cycling & What is the input voltage or current waveform (e.g. Voltage step, voltammetry, swept sine). \\
\hline Voltage Min. (V) & The lowest voltage used in operating the actuator (e.g. $0 \mathrm{~V}$ or $-10 \mathrm{~V}$ ) \\
\hline Voltage Max. (V) & The maximum voltage applied (Peak to Peak). \\
\hline Voltage Difference $(\mathrm{V})$ & The amplitude of the applied voltage. \\
\hline Prestrain (Primary Axis) (\%) & The relative amount by which the actuator is pre-stretched along the direction of actuation. \\
\hline Prestrain (Secondary Axis) (\%) & $\begin{array}{l}\text { The relative amount by which the actuator is pre-stretched perpendicular to the direction of } \\
\text { actuation. }\end{array}$ \\
\hline Constant Load $(\mathrm{N})$ & Magnitude of force applied when operated under fixed load conditions. \\
\hline Frequency (Hz) & Number of actuation cycles per second. \\
\hline \multicolumn{2}{|l|}{ Experiment Results } \\
\hline Work Density $\left(\mathrm{kJ} / \mathrm{m}^{\wedge} 3\right)$ & $\begin{array}{l}\text { The amount of work generated per unit volume of active material (not including packaging, } \\
\text { electrodes, electrolyte etc.) }\end{array}$ \\
\hline Typical Strain (\%) & The strain that is typically observed. \\
\hline Operating Stress (MPa) & The load normalized by the cross-section area. \\
\hline Power Density $(\mathrm{kW} / \mathrm{m} \wedge 3)$ & The mechanical power per unit volume. \\
\hline Continuous Power ( $\mathrm{W} / \mathrm{kg}$ ) & The average mechanical power under continuous actuation. \\
\hline Cycles (Minimum) & $\begin{array}{l}\text { The number of cycles at which strain (or stress under isometric conditions) drops to half of its } \\
\text { initial value. }\end{array}$ \\
\hline Efficiency (\%) & The ratio of the mechanical work out to the electrical energy in. \\
\hline $\begin{array}{l}\text { Electrochemical Strain } \\
\text { Coefficient }\left(\% /\left(C / m^{\wedge} 3\right)\right)\end{array}$ & $\begin{array}{l}\text { The amount of strain obtained per unit charge, per unit volume (primarily for conducting } \\
\text { polymers.) }\end{array}$ \\
\hline Charge $(\mathrm{mC})$ & The absolute amount of charge transferred. \\
\hline Capacitance (F) & The total capacitance of the cell. \\
\hline Bandwidth $(\mathrm{Hz})$ & The rate at which the actuator strain (or stress) drops by $50 \%$. \\
\hline Strain Rate $(\% / s)$ & The average strain per unit time. \\
\hline Stress Rate (MPa/s) & The average stress per unit time. \\
\hline $\begin{array}{l}\text { Stress Relax Rate (Active) } \\
\text { (\%/cycle) }\end{array}$ & The average rate at which stress changes under constant load. \\
\hline $\begin{array}{l}\text { Stress Relax Rate (Inactive) } \\
\text { (\%/cycle) }\end{array}$ & The peak rate at which stress drops (under isometric conditions). \\
\hline Creep Rate (Active) (\%/cycle) & The peak rate of creep during actuation (typically under constant load) \\
\hline $\begin{array}{l}\text { Creep Rate (Inactive) } \\
\text { (\%/cycle) }\end{array}$ & $\begin{array}{l}\text { The maximum rate at which creep is observed under fixed electrical conditions (typically at } \\
\text { constant load) }\end{array}$ \\
\hline Peak Power (W/kg) & The maximum observed mechanical power per unit active material mass \\
\hline Peak Engineering Strain (\%) & The maximum strain observed. \\
\hline Average Strain Rate $(\% / s)$ & The typical strain rate. \\
\hline Average Stress Rate (MPa/s) & The rate at which stress is changing (primarily calculated for isometric measurements). \\
\hline Charge/Nolume $\left(\mathrm{mC} / \mathrm{m}^{\wedge} 3\right)$ & The amount of charge transferred per unit volume of active material. \\
\hline Charge $/$ Mass (mC/kg) & The amount of charge transferred per unit mass of active material. \\
\hline Capacitance Nolume $\left(\mathrm{F} / \mathrm{m}^{\wedge} 3\right)$ & The charge divided by the voltage, normalized by volume. \\
\hline Electric Field Intensity $(\mathrm{V} / \mathrm{m})$ & The intensity of the electric field applied (primarily used to describe actuation in dielectrics). \\
\hline \multicolumn{2}{|l|}{ Source Information } \\
\hline Source & $\begin{array}{l}\text { A reference to the publication from which the data are obtained or, if unpublished, the group } \\
\text { from which the data originated. }\end{array}$ \\
\hline Author & The names of the authors or providers of the data. \\
\hline
\end{tabular}

Fig. 5. A brief description of the fields used to describe each actuator experiment. 


\subsection{The Database Browser}

The DATABASE BROWSER allows the database to be scanned, and data to be selected by mechanism and material. Mechanism refers to the type of electroactive polymer actuator - for example it can be a conducting polymer (CP), a carbon nanotube actuator (CNT) or a dielectric elastomer (DE). Selection may also be made by material - e.g. the type of silicone, or the particular conducting polymer (polyaniline or polypyrrole for example).

In the database browser a list of entries appears which may be sorted by mechanism, material, strain, strain rate, stress, energy density, power density and source. Sorting is currently done in ascending alphabetic or numerical order, as appropriate to the category. Clicking the category multiple times will enable sorting in descending order to be obtained once the next round of upgrades is performed.

Figure 6 shows the results of a sort by operating stress, indicating that the highest stresses obtained are from polyaniline fiber-based actuators. This is perhaps not surprising since these fibres have a high degree of polymer chain alignment along their axes. Other properties are easily viewed, revealing that strains are relatively small in these fibres, also as expected given their chain orientation and the common hypothesis that strain is the result of ion insertion between chains. The complete set of fields associated with a given experiment is accessed by selecting the sheet symbol in the far right hand column (producing a listing as in Figure 4).

Note that the database is not yet complete. This is evident from the list of high stress actuation results, in which relaxor ferroelectric polymers are completely absent, for example.

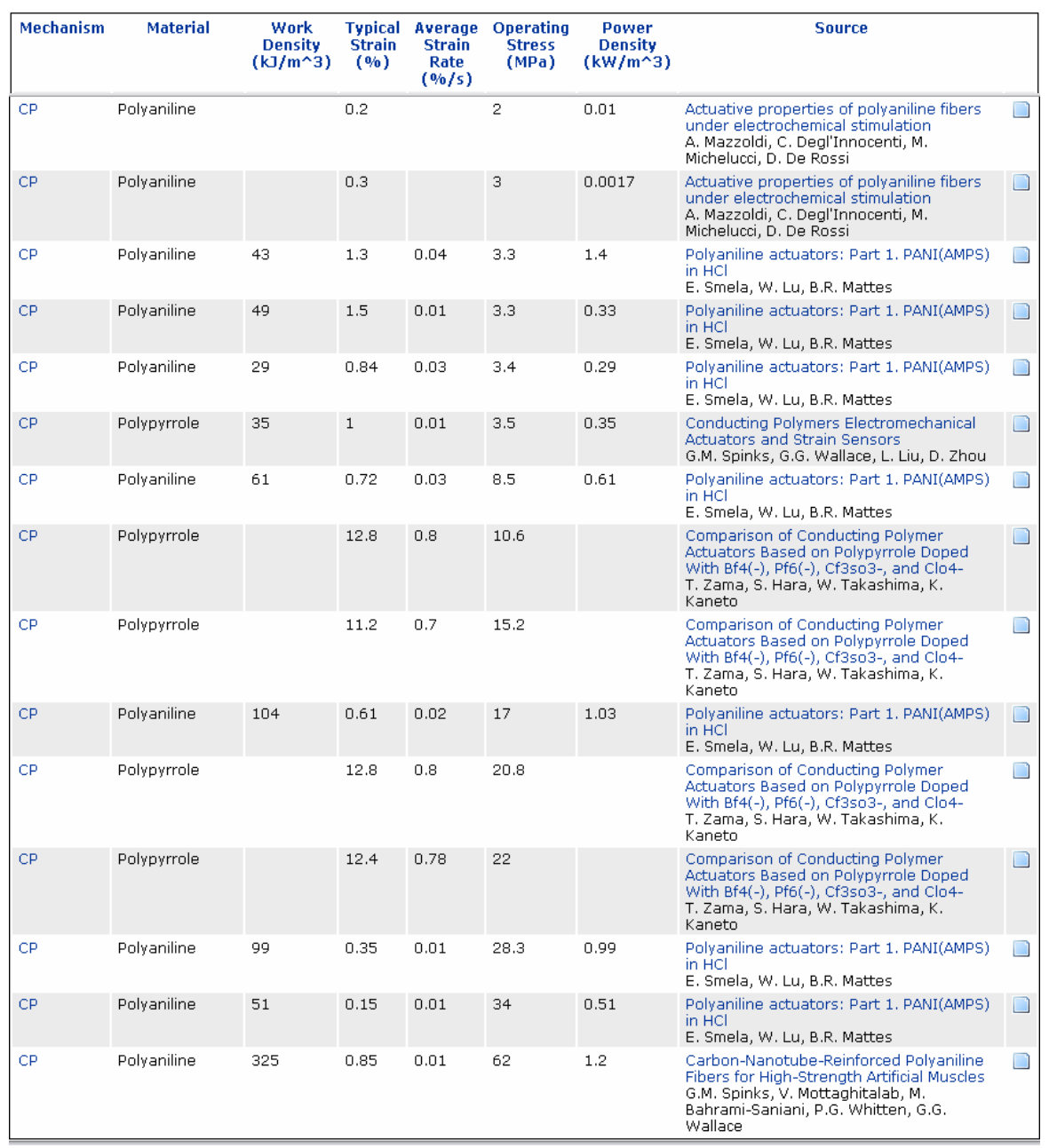

Fig. 6. Listing of database entries in ascending order of operating stress. Only the bottom of the table is shown. 


\subsection{Data Entry}

Users who have collected data on actuators may enter their own data via an online form. The form has the same fields as the lists shown in Figures 4 and 5. In order to do so a password needs to be obtained from the site administrator. The data is reviewed by the site administrator and may also be sent out to be reviewing by researchers with relevant expertise. Ideally the online submission will be supported by an emailed document submission containing some details of the experimental conditions and plots of the data from which performance has been extracted. This supporting material may be in the form of a journal article, but would ideally be more complete and contain more of the raw data than a journal article typically does.

\section{DISCUSSION AND CONCLUSION}

A number of review articles and books have been written on electroactive polymers ${ }^{1,2}$. These provide valuable descriptions of mechanisms and performance. However in the absence of highly complex models relating operating conditions and material properties, it is important to have access to up to date experimental data in order to obtain a true picture of performance. The actuator database presented provides a platform into which this data can be entered. The mechanisms of presenting the data as well as evaluating the inputs have been presented.

\section{REFERENCES}

1. $\quad$ Madden, J. D. W., et al., Oceanic Engineering, IEEE Journal of (2004), 29, 706

2. $\quad$ Bar-Cohen, Y., Electroactive polymer (EAP) actuators as artificial muscle. 2nd ed.; SPIE: Bellingham, WA, (2004) 